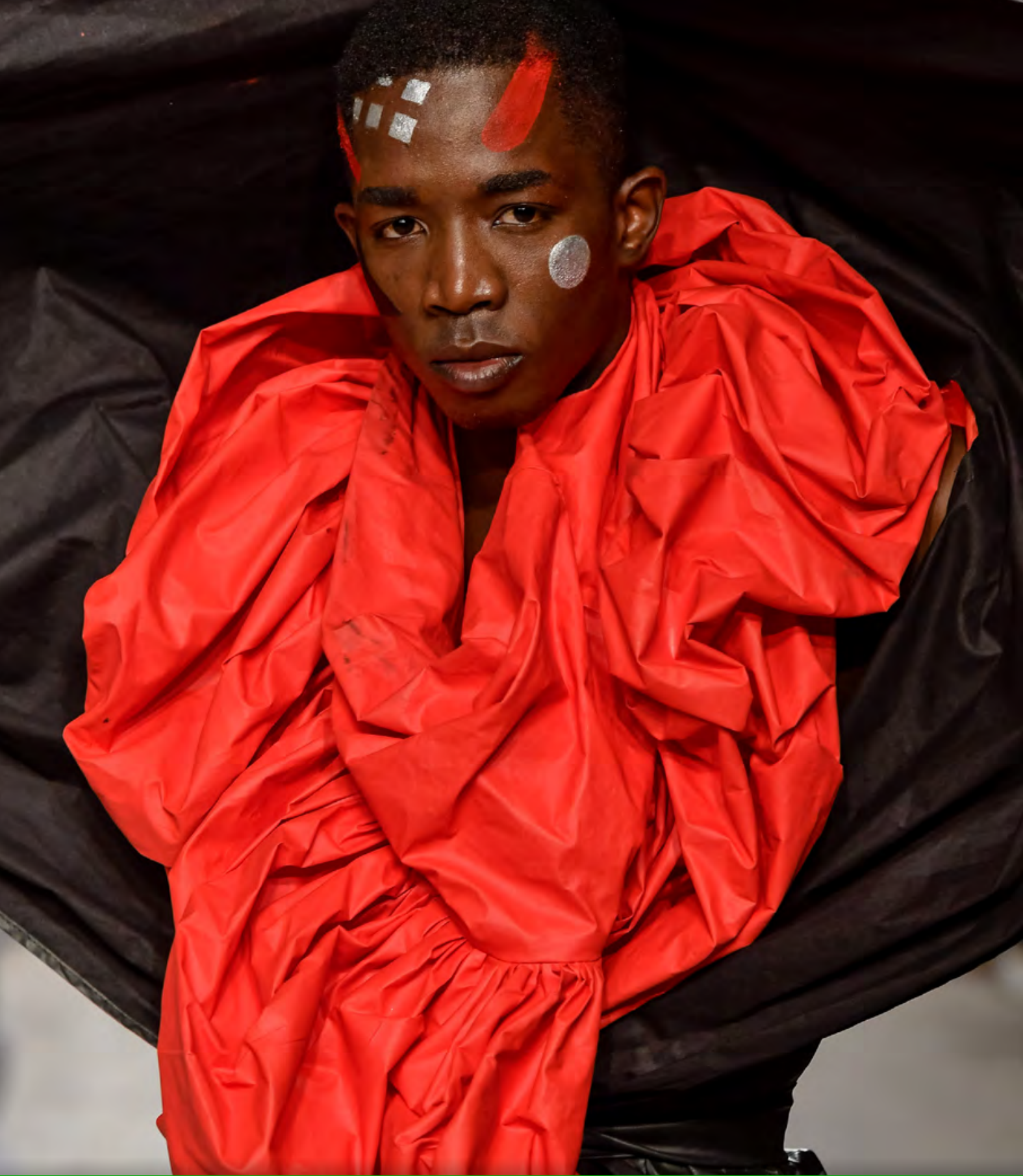

\title{
Censura das cópias na indústria da moda
}

Copies censorship in fashion industry 


\section{[HUMBERTO PINHEIRO LOPES]}

Doutor em Estudos Contemporâneos. Professor do curso de Moda, Design e Estilismo do Centro de Ciências da Educação (CCE) da Universidade Federal do Piaui (UFPI).

E-mail: lopes.humbert@gmail.com

[resumo] Este artigo aborda, por meio de uma pesquisa bibliográfica, a censura da prática das cópias não autorizadas frente à produção na indústria da moda e à legislação favorável à propriedade intelectual. 0 texto é um excerto de uma pesquisa (LOPES, 2017) do doutorado em Estudos Contemporâneos (DEC) do Instituto de Investigação Interdisciplinar (IIIUC) da Universidade de Coimbra (UC). A censura direcionada à prática das cópias na indústria da moda surge a partir de uma resistência dessa prática em razão de seu intenso poder de transgressão, acesso ao sistema produtivo e alcance do consumo.

[palavras-chave]

censura; indústria da cópia;

propriedade intelectual.

[abstract] This paper aims, through a bibliographic research, to discuss the censorship of non-authorized copies, considering fashion industry production and intellectual property legislation. This text is part of a Contemporary Studies PhD research (LOPES, 2017) linked with the Institute for Interdisciplinary Research of the University of Coimbra. The censorship related to copy practice in fashion industry arises from a resistance due to its strong power of transgression, access to the production system and the socialization of consumption.

[keywords] censorship; fashion industry; intellectual property. 


\section{Introdução}

Este artigo é resultado de uma pesquisa de doutorado (LOPES, 2017) vinculada ao curso de Estudos Contemporâneos (DEC) do Centro de Estudos Interdisciplinares do Século XX (CEIS20) do Instituto de Investigação Interdisciplinar (IIIUC) da Universidade de Coimbra (UC). A tese de doutorado avaliou como, em que medida e com quais implicações produtos copiados de moda são comercializados mediante a criminalização corroborada pela legislação e por uma censura social revelada pela cultura que a repudia.

Para este artigo, foi selecionada uma parte da investigação doutoral relacionada à resistência da prática das cópias não autorizadas frente à produção na indústria de moda e à legislação favorável à propriedade intelectual. Por meio de uma pesquisa bibliográfica, são elencadas as reflexões sobre um sistema produtivo e o mercado referente à indústria de moda, indicando as construções de âmbitos formal e legal para restringir o conhecimento, ao caracterizar o panorama das cópias não autorizadas. Apesar da necessidade do emergente policiamento e da delimitação dos direitos de propriedade intelectual perante às novas tecnologias de reprodução, são demonstrados os paradoxos e as contradições da indústria da cópias. Neste artigo, é indicado o caráter transgressor e de natureza disruptiva que as cópias podem ter, ao beneficiar um sistema que as condena e que delas dependem.

Neste artigo, é feita uma diferença entre o uso da palavra "moda" escrita como substantivo próprio e comum. No primeiro caso, "Moda" concerne ao estudo dos movimentos culturais das mudanças de comportamentos e hábitos de uma sociedade. No segundo caso, "moda" dirige-se a uma situação particular e efêmera, como um produto que apresenta sucesso momentâneo em um período determinado, que não passa de um mês. $A$ palavra "moda" também compreende a indústria que abrange o setor de vestuário, calçados e acessórios (LOPES; VERAS, 2012). Essa diferenciação é utilizada na dissertação de mestrado de Mesquita (2000) e no seu livro Moda contemporânea (MESOUITA, 2010).

Outra palavra merece no artigo um esclarecimento: design. Conforme Santos (2013), a palavra design tem sido banalizada. É possivel encontrar o uso dessa palavra em âmbito mais popular como o sinônimo de desenho, caracteristica formal ou estilo (quando se projetam artigos de luxo) $e_{\text {, }}$ constantemente, pode se referir a um produto que está na moda, conforme aponta Azevedo (2014). Ambos os autores percebem o design como projeto, designação que vem da sua origem do inglês. Azevedo (2014) também acrescenta que, quando se lida com os meios de reprodução, a palavra design se refere ao estilo da cópia. Azevedo (2014) ainda afirma que, no momento em que um artefato é transformado em um objeto de cópia, 
ele não é mais desenho, é um design. Ele ainda pondera que design está relacionado ao processo de produção em série. Para este artigo, a palavra design será mais utilizada no contexto de um objeto de cópia, fruto de uma produção em série, conforme a visão de Azevedo (2014), ainda que haja alguma perspectiva do significado relativo a projeto.

0 artigo é dividido pelos seguintes tópicos: "A indústria da cópia", ao abordar tal indústria como elemento transgressor no setor de moda e vestuário, indicando a discussão de autores como Jacob et al. (2014) e Martineli (2011); e "A (des)vantagem da propriedade intelectual", ao atentar para a questão dos direitos deste tipo de propriedade, restringindo 0 conhecimento de uma forma que o coloca mais distante do acesso da população mundial, além de mostrar, como, na Moda, esse distanciamento pode ser um paradoxo no que concerne à produção de cópias. Nesse último tópico, são discutidas as reflexões de autores como Raustiala e Springman (2006) e Sinnreich e Gluck (2005). Por fim, é possivel perceber as cópias como um elemento disruptor, de resistência, em meio às restrições operadas por meio da atuação do mercado e da legislação favorável à propriedade intelectual.

\section{A indústria da cópia}

Jacob et al. (2014) revelam que as cópias se tornam importantes nos diversos setores da economia, como a confecção de vestuário, pois funcionam como uma estratégia facilitadora para a disseminação de tendências. Considerando que a comercialização de falsificações (uma das modalidades das cópias) é uma atividade ilegal, a produção de cópias é mais aceita se for acompanhada de uma perspectiva de inovação, quando se insiste na formação de um mercado com identidade própria. A inovação e a agilidade para introduzir elementos considerados novos na produção podem funcionar como táticas para consolidar a aceitação do público-alvo em um mercado competitivo. A disseminação de cópias fomenta a introdução de elementos a partir do desenvolvimento da Moda, ao consagrar a inovação como um princípio (LIPOVETSKY, 2005). Devido a isso, a incursão pela novidade torna-se "fonte de valor moderno, sinal de superioridade social" (BALDINI, 2006, p. 41). As cópias, no mercado de Moda, consagram a propagação da novidade, ao difundirem os novos elementos propiciados pela dinâmica da obsolescência.

0 desenvolvimento da indústria é pautado por uma liderança no investimento em design, desde que considere os preceitos de uma educação que valorize a criatividade. São associados elementos que fortalecem a indústria criativa e protegem os bens que produz, divergindo de qualquer produção que não se alinhe à sua estrutura. 0 design surge como uma das características que alavanca a vantagem competitiva no mercado que a 
indústria da cópia ameaça. Por essa razão, as cópias devem ter seus limites: Jacob et al. (2014) recomendam que a inovação seja inserida gradativamente no desenvolvimento do produto com o propósito de suplantar a imitação anterior. Caso a incidência de cópia continue, a prática pode tornar-se um obstáculo para o desenvolvimento da pesquisa e da tecnologia, o que pode causar efeitos deletérios para a indústria regional, porque a cópia refreia a inovação (RAUSTIALA; SPRINGMAN, 2006). Essa afirmação é um anúncio sobre uma das perspectivas que reconhece na indústria da cópia a responsabilidade por desencorajar futuros investimentos em novas criações e invenções.

A insistência dos efeitos e dos problemas que a prática das cópias causa está, em parte, relacionada aos prejuizos que acarretariam ao setor industrial (LOPES, 2014). A inovação, no mercado que suporta a indústria criativa, surge como um caminho salvador que deve ser percorrido por meio de um apelo ao investimento em design. Como consequência, é creditada ao ensino a adequação de medidas criativas, preterindo a produção de cópias, ainda que, para ensinar a prática da confecção de produtos considerados originais, devam ser seguidos modelos que reproduzem as estratégias do mercado, copiando exemplos de sucesso.

0 reforço à censura das cópias é acompanhado de uma série de orientações que indicam a maneira adequada e consciente de produzir bens de cunho criativo. Os discursos partidários à censura centram-se em alegações de que a produção de cópias não favorece o desenvolvimento de pesquisas, o que diminuiria o investimento em tecnologia. A prática das cópias, por consequência, teria como solução a inserção gradual da inovação para a pesquisa e o desenvolvimento de produtos. Se a inovação emerge para os empreendedores como uma vantagem do ponto de vista da prosperidade econômica (DORION et al., 2012), o mercado deve atender às necessidades de um público que prefere consumir a considerada inovação. Dorion et al. (2012) reforçam que a inovação permite o desenvolvimento de novos produtos ou serviços para o mercado, como também estimula o interesse em investir em negócios recém-surgidos. Essa inovação refere-se à capacidade produtiva em pesquisa e tecnologia voltada à indústria criativa.

A posição dos defensores da indústria criativa encontra diferenças, pois, de um lado, defendem a difusão das cópias para disseminar a inovação; de outro, elevam a criação como suporte para o desenvolvimento de produto. Se a introdução das cópias no mercado gera inovação, o consumo delas, ao invés de trazer prejuizos para o mercado, expande-o mais ainda. De fato, Raustiala e Springman (2006) declaram que a cópia pode promover inovação e beneficia criadores. Essa contradição que mostra o potencial econômico da cópia é chamada por esses autores de paradoxo da pirataria. 
0 problema incide no poder de difusão: o mercado tenta coibir a difusão das cópias, fazendo o possivel para que não ultrapassem o valor creditado aos bens protegidos pela indústria criativa. As cópias devem ser consumidas com moderação, desde que não atrapalhem a geração de receita da indústria criativa. Quanto menos se souber das vantagens competitivas das cópias, mais fácil será convencer o público dos benefícios dos bens da indústria criativa, sem que as cópias causem prejuízos de ordem financeira.

A indústria criativa tem seus bens de natureza simbólico-cultural sujeitos aos direitos de proteção intelectual, apontados como marcos reguladores de desenvolvimento. Assim, esses bens tornam-se ativos de valor de uma organização. Para isso, fundamenta-se uma perspectiva da intervenção dos poderes públicos com o propósito de proteger o patrimônio em auxilio às políticas de fomento para as práticas que envolvam atividades artisticas, culturais e criativas (LIMA, 2007).

A defesa do patrimônio sustentada pelo mercado reforça uma ideia de que a indústria da cópia mais diminui o sistema consolidado pela inovação do que aumenta as cifras econômicas das empresas ligadas à indústria criativa. Restringindo o domínio de alcance da produção e do conhecimento, as iniciativas pública e privada desenvolvem estratégias, ao delimitarem que o uso de objetos indicados por incentivos políticos e empresariais é aprovado e qualquer produto que esteja fora dessa esfera é condenável por lei. Conforme Martineli (2012), isso ocorre porque as cópias são consideradas como componente caótico e desorganizador, revelando incoerências institucionais, já que sua prática facilita o acesso a bens e mercadorias cercados de diretrizes condicionadas por restrição. Isso implica uma tentativa de moldar representações consolidadas como adequadas: os efeitos da influência do mercado circulam dentro do próprio discurso que fortalece o reconhecimento de normas, orientações e valores contrários à prática das cópias.

A censura às cópias alavanca um discurso político relacionado à falta de recolhimento dos direitos de propriedade intelectual, à sonegação de impostos e à usurpação dos direitos da empresa sobre o produto (BRANDÃO, 2011). A comercialização de produtos falsificados, ao passo que se constitui como uma ameaça para a hegemonia do mercado formal, também propicia alternativas para um sistema que a marginaliza e a exclui. A prática das cópias é um desvio nesse contexto. Martineli (2011) afirma que o consumo de bens piratas é uma modalidade de consumo desviante, adotando esta ideia por meio do conceito de desvio proposto por Becker (1973), ao estipular o desvio como "algo que existe na interação, e não no próprio comportamento" (MARTINELI, 2011, p. 18). A autora também associa esse conceito à ideia de acusação: "não existem desviantes em si 
mesmos, mas uma relação entre atores (indivíduos, grupos) que acusam outros atores de estarem consciente ou inconscientemente quebrando, com seu comportamento, limites ou valores" (VELHO, 2003, p. 23 apud MARTINELI, 2011, p. 18) de um contexto sociocultural.

A comercialização das cópias populariza um produto, contudo torna-se "um problema quando ameaça a apropriação exclusiva de bens de alto valor simbólico" (BRANDÃO, 2011, p. 198). Caracterizadas como uma face espectral das políticas em favor da indústria criativa e das dinâmicas hegemônicas de divulgação da informação, as falsificações são dissidentes de um padrão instituido a partir de normas que legitimam maneiras de ver objetos, consumidores e comerciantes. Tal legitimação é estabelecida pela postura como são encaradas as imagens que reforçam a consolidação da prática das cópias fora da esfera criativa.

As imagens representam visões ideológicas conservadoras e "podem manipular estereótipos valendo-se de juízos de valor, avaliações e hierarquias que buscam estabelecer verdades 'perenes'" (MARTINS, 2009, p. 3720). 0 autor ainda pondera sobre um mundo simbólico com suas formas construídas culturalmente e mediadas por tradições, onde as imagens, situadas socialmente, representam um espectro ideológico. As cópias, que circulam pelas feiras e pelas ruas dos centros urbanos, são fragmentos de representações ideológicas de imagens difundidas por grupos socialmente dominantes. 0 poder que as imagens hegemônicas possuem aspira em "transformá-las em monólogo, em verdade, dotando-as de um caráter essencialista e universal" (MARTINS, 2009, p. 3720), o que faz eclipsar uma posição adequadamente consolidada para as cópias. As imagens são domadas por um discurso construído que estabelece normas e orientações, ao consagrar o lugar do original no mercado e, consequentemente, desprezar as cópias como objetos famigerados.

As cópias recebem os sentidos mais abjetos porque são uma ameaça para o sistema de produção da indústria criativa. Como uma ameaça, é priorizada sua falta de adequação corroborada nos âmbitos educativo, legislativo e moral. Todavia, a prática das cópias resiste às sanções que lhe são impostas. Resiste porque a comercialização de produtos falsificados revela um benefício para o usuário que, ao desejá-los, encontra satisfação em razão do acesso que essas mercadorias propiciam, seja pelo preço ou pela reinterpretação de ajustes de aspectos simbólicos (cor, formato, mar$\mathrm{ca}$, entre outros), reestruturando propostas já utilizadas no mercado.

Assim, nivelam-se procedência e qualidade, classificando e dividindo características de gosto e adequação ao consumo mediante uma visão hierarquizada que constitui as visões pautadas também pela indústria da 
moda. Porém, a produção e a circulação que difunde as cópias são resistentes a uma hegemonia da indústria criativa, fugindo de rotas estabelecidas pelo mercado formal. 0 design ofertado pela indústria criativa também pode ser componente presente nas cópias, pois cada vez mais há produtos que se aproximam da qualidade ofertada a bens originais.

À proporção que as cópias ganham espaço nas práticas sociais por meio da difusão da Moda, vão surgindo bases de fundamento jurídico que recorrem à proteção dos direitos de criadores e inventores. A prática das cópias ganha dimensão mundial quando a cooperação de acordos internacionais em favor à sua censura reúne governos interessados em barrá-la, esboçando-se os primeiros tratados favoráveis à proteção de direitos da propriedade intelectual, como a Convenção de Paris, em 1883, acordo que tratou em especifico sobre os direitos de propriedade industrial, e a Convenção de Berna, em 1886, na Alemanha, que acertou sobre os direitos de propriedade artística e literária (MARINHO; OLIVEIRA, 2014).

\section{A (des)vantagem da propriedade intelectual}

Enquanto os bens materiais são compostos por elementos físicos, bens de natureza imaterial são caracterizados pelas suas formas intangiveis ou não físicas. Ainda assim, as criações intelectuais são, na maior parte dos casos, retidas em algum formato tangível. A diferença mais marcante entre a propriedade dirigida a objetos tangíveis e os direitos de propriedade intelectual é o tempo limitado para cada proteção que o último tipo de propriedade garante. As marcas registradas são uma exceção à regra: enquanto o registro é limitado usualmente pelo tempo, ele pode ser renovado infinitamente e a marca registrada permanece válida pelo tempo em que é utilizada (registrada) no mercado (KUR; DREIER, 2013). A propriedade intelectual refere-se à proteção legalmente reconhecida, cobrindo os direitos sobre tipos de criatividade intelectual. Essa cobertura inclui os direitos de autor, as marcas, as patentes etc., configurando-se como um produto do intelecto humano que possui algum valor de mercado. Parte dos países europeus faz uso do termo propriedade industrial para se referir a uma parte da propriedade intelectual, como as marcas e as patentes. No Brasil, o termo recorrente para a proteção de marcas e patentes é objeto da propriedade industrial, regida por regulamentação própria: a Lei de Propriedade Industrial (LPI), em vigor no Brasil desde 15 de maio de 1997 (BRASIL, 1996).

As legislações de diferentes paises atuam também conforme acordos internacionais com variações delimitadas por esses acordos e normas internas de cada nação. Considerando a diferença entre as legislações, algumas situações são costumeiramente alvo de questionamentos, inclusive, de notícias jornalísticas, devido à sutileza daquilo que é protegido ou não 
por lei. No caso europeu, em específico, há uma discussão em âmbito jurídico que esclarece uma ambiguidade em relação à adoção de formas e cores como propriedade. Como exemplo disso, há o caso das solas vermelhas dos sapatos femininos da marca francesa Christian Louboutin. 0 Tribunal de Justiça da União Europeia (TJUE) já informou que "uma marca que consiste em uma cor aplicada na sola de um sapato não é abrangida pela proibição de registo de formas" (AFP, 2018). Há uma sutileza na declaração do TJUE, ao destacar a referência a uma cor aplicada nas solas dos sapatos. É uma referência que traz uma particularização ao caso de cores, em especial, pois esse mesmo tribunal já mostrou que houve patenteação errônea do reconhecido padrão xadrez marrom e bege da francesa Louis Vuitton (BOSTEELS, 2015; KILCOOLEY-O'HALLORAN, 2015). A interpretação da lei mostra a sutileza das determinações, ao referenciar aquilo que é original e cópia. A Louboutin teve uma causa ganha em 2018 na justiça europeia. A partir disso, mostra-se como são encarados os produtos das marcas que usaram o que agora passa a ser considerado propriedade da Louboutin: cópias não autorizadas.

A proteção à propriedade intelectual é complexa, do ponto de vista conceitual e da análise jurídica, em razão das diferenças entre as legislações e da ambiguidade gerada por algumas jurisprudências. Apesar de serem fornecidas algumas direções neste artigo, é necessário ressaltar que a definição de cópia, falsificação e pirataria é de natureza cultural, mas também jurídica. Tais diferenças são levantadas em outros estudos (cf. LOPES, 2017). Para este excerto, é considerado de forma mais simplista o que é cópia, falsificação e pirataria tudo aquilo que, nos casos de proteção à propriedade intelectual, não tenham ao menos uma jurisprudência. Aqueles casos, em âmbito judicial, que têm causa ganha, ainda que não seja em última instância, mostram uma abertura para que sejam considerados originais o produto de litígio. Isso porque há uma segurança, mesmo que momentânea, que goza de um direito.

Além disso, apesar de haver alguma diferença entre os termos propriedade intelectual e propriedade industrial, a partir daqui se adota o termo propriedade intelectual como cobertura dos direitos de propriedade industrial. Existe uma aceitação, em termos jurídicos, de se considerar a propriedade industrial como uma parte da propriedade intelectual em diversos paises europeus e, inclusivamente, no Brasil. A propriedade intelectual em causa se dirige aos ativos intangiveis.

A proteção de ativos intangiveis é concernente a uma propriedade particular que, por um lado, resguarda direitos de criações e invenções; e, por outro, é acusada de restringir o conhecimento cada vez mais distante da produção amadora. Na contramão da produção amadora, a falta de acesso 
ao conhecimento, cada vez mais privatizado, impossibilita a inovação e a produtividade (SCHWEIDLER; COSTANZA-CHOCK, 2005). 0 conhecimento, produto das "interações e das comunicações não comerciais" (GORZ, 2005, p. 31), tornou-se uma relevante força produtiva, indicando que o valor de troca das mercadorias, "sejam ou não materiais, não é mais determinado em última análise pela quantidade de trabalho social geral que elas contêm, mas, principalmente, pelo seu conteúdo de conhecimentos, informações, de inteligências gerais" (GORZ, 2005, p. 29). "Valor", a partir do sentido econômico, alude ao valor de troca de uma mercadoria em relação a outras. Gorz (2005) reforça que o conhecimento se torna propriedade exclusiva da empresa que o valoriza, incorporando-o nas mercadorias produzidas.

De acordo com Sant'anna (2007), o conhecimento difunde-se por quatro agentes: o poder desfrutado por alguns, autorizados a apropriarem-se do conhecimento; os valores, ao influenciarem e serem influenciados pelo conhecimento desenvolvido; a razão, que se refere à forma como o conhecimento pode produzir mudanças sem consequências pretendidas; e a própria circulação do conhecimento, ao produzir uma ideia de que não "há objeto inerte diante de sua própria reflexão e que não se atualize a partir dela" (SANT'ANNA, 2007, p. 27). 0 primeiro agente mais se aproxima das práticas relativas à propriedade intelectual. A difusão do conhecimento é influenciada pelas relações de mercado que podem favorecer a origem de um monopólio certificado por um contexto jurídico e político.

Apesar disso, há movimentos de acesso ao conhecimento que tentam alterar paradigmas estabelecidos pela restrição da lei, como a adoção do software livre (SILVEIRA, 2005), o reconhecimento da atividade amadora a partir da produção imagética autônoma (ARAÚJ0, 2011) e o livre acesso à produção científica (MUELLER, 2006). Na Moda, o acesso ao conhecimento encontra obstáculos devido à forma como são encaradas as leis de proteção à propriedade intelectual. 0 interesse sobre o conhecimento das técnicas e das formas dos produtos de moda gera disputas financeiras pela legitimidade reclamada por uma marca ou outra, levando em conta a abrangência de seus interesses privados (ANSA, 2014; MCDOUGALL, 2011; PAZ; SCHIMIDT, 2015). A natureza desses interesses presta-se dificilmente a questões que atendam ao progresso e ao desenvolvimento social, pois estão associados à manutenção de riquezas de monopólios.

A indústria da moda está regida por disposições legais de dimensão internacional, envolvendo temas que se relacionam com a propriedade intelectual, comércio eletrônico, contratos de franquias, de distribuição e de licenças, direito administrativo, direito comercial, direito do consumidor, direito laboral, além de relacionar-se a aspectos alfandegários e tributários 
(KNOLL; ECHEVERRIA, 2014). A investigação e a produção de conhecimento, nesse rol de disposições, estão restritas, mantendo exclusividade e limitações sobre a fabricação, a comercialização e o consumo de produtos de moda. Constitui-se um sistema gerido também por uma indústria que se cerca de uma lógica em que a diferença entre cópias e originais é operada sob o circuito da propriedade.

A indústria da moda compreende um sistema que depende da defesa à propriedade intelectual, dirigindo-se a uma ênfase que defende 0 aspecto econômico (KRETSCHMANN, 2015). 0 sistema tende a excluir o livre acesso ao conhecimento e constrói um modelo vertical que privilegia uns e relega outros, assim como indaga Lo (2005): "Não vivemos nós em um mundo no qual alguns grupos industriais dos paises do Norte, ao monopolizarem algumas patentes ou licenças, conseguem impor aos demais (a maioria) limites para o uso de obras e de trabalhos?" A exemplo do monopólio do Norte, Lo (2005) acrescenta que o investimento em patentes nos paises industrializado é maior, concentrando $97 \%$ dos registros, fazendo com que passem a exigir um alinhamento unilateral de suas formas pelos paises em desenvolvimento.

No topo, em vantagem, encontram-se os paises desenvolvidos, "que dispõem de sistemas de proteção à propriedade nos quais o público deposita um certo grau de confiança" (SHERWOOD, 1992, p. 11). Isso ocorre, segundo Sherwood (1992), graças à forma como o grau de desenvolvimento econômico desses países afeta a proteção do copyright, das expressões criativas, das invenções e das marcas registradas. Concomitante à assistência da legislação dos direitos de propriedade intelectual, parte dos meios de comunicação conduz à formação de uma opinião pública em que os produtos falsificados são impróprios para o uso da população, pois são de origem danosa, inclusive, para o consumidor.

$\mathrm{Na}$ tentativa de seguir o modelo do patrimônio material, a propriedade intelectual constitui-se por normas jurídicas para a proteção do design de produtos, das invenções, das marcas registradas etc. (LO, 2005). Esse tipo de propriedade confere a seus detentores o direito sobre a materialização de um trabalho ou uma invenção (KINSELLA, 2008). A propriedade intelectual é um tema que se consolida em âmbito internacional devido à facilidade relacionada ao reconhecimento da prática das cópias como atividade emergente da difusão de bens imateriais. A proteção jurídica reconhece um direito a esse tipo de propriedade por um maior número de paises e internacionaliza o processo de consolidação desses direitos (MARINHO; OLIVEIRA, 2014), organizando atividades supranacionais ao integrarem governos que apoiam a causa em desfavor da prática das cópias não autorizadas. 
A regulamentação atual dos direitos de propriedade intelectual age como um obstáculo em um mundo onde todos podem produzir e trocar informações. Ainda que as invenções mereçam ser recompensadas pelos esforços empreendidos por cada descoberta, deve-se evitar o favorecimento de exclusividade a detentores que engendrem um monopólio favorável aos direitos de propriedade. 0 monopólio resulta na implementação de medidas que proíbem o uso de bens e serviços essenciais para o desenvolvimento igualitário da sociedade mundial. Levando em conta a relevância do acesso democrático das informações para o bem-estar humano, para a educação e para o desenvolvimento econômico equilibrado e sustentável, é necessário que se assegure a proteção intelectual pelos governos em favor da sociedade civil. 0 mercado não deve ditar normas que estabeleçam uma situação em que as corporações da indústria da moda restrinjam a circulação do conhecimento. A inclusão do acesso ao conhecimento é necessária, pois a informação deve funcionar como benefício para todos. $A$ harmonização dos direitos de propriedade intelectual deve passar por um reequilíbrio em que proprietários e usuários possam se favorecer do acesso ao conhecimento à informação (LO, 2005). A legislação deve adaptar-se à realidade do conhecimento compartilhado e a novos conceitos que proporcionem compensação exigida pela criação, porque a cópia existe e ninguém pode pará-la (MUSTONEN, 2013).

Contrária ao benefício que o conhecimento da propriedade intelectual possa gerar para o desenvolvimento social, a pesquisa privada torna a conquista do lucro uma atividade mais relevante do que a utilidade social alcançada pela investigação (GORZ, 2005). Ao reter a exclusividade da circulação de informações, a propriedade intelectual ampara a concentração de capital, decorrente também do aumento de aquisições e fusões entre as empresas (COSTA, 2014), tornando o mercado uma convenção privilegiada para que ocorram transações financeiras milionárias longe do alcance das riquezas pela maior parte da população mundial. Em relação a isso, Brandão (2009) denuncia que os obstáculos à circulação de cópias nunca foram tão evidenciados como têm sido: os governos e a iniciativa privada se apoiam em organizações respaldadas por condutas e orientações de dimensão jurídica, moral e política. Os direitos favoráveis à propriedade intelectual representam uma questão política que deve ser discutida tanto pelos governos como pela sociedade civil, e não somente direcionadas pelos interesses econômicos, como atesta Barbosa (2003). Apesar do autor afirmar que as leis de propriedade intelectual são elaboradas mediante uma participação democrática de todos os interesses econômicos envolvidos na questão, Barbosa (2003) aborda tais interesses como influentes neste âmbito que considera democrático, elevando a economia como alavanca para se perceber o funcionamento e a aplicação do regime democrático frente ao favorecimento dessas leis. 
Considerando isso, o regime atual de propriedade intelectual é uma ameaça à democratização da educação, da participação cívica e da proteção de uma herança compartilhada do conhecimento e da criatividade (SCHWEIDLER; COSTANZA-CHOCK, 2005). Tal ameaça origina exclusividade para uma parcela reduzida da população mundial que detém o domínio sobre o capital comercial, financeiro e humano. No que tange à indústria da moda, Raustiala e Springman (2006) argumentam que o regime de baixa proteção à propriedade intelectual proporciona uma livre apropriação de designs que acelera a difusão de estilos. Os autores chamam esse processo de aceleração de obsolescência induzida. Se as cópias tornam-se ilegais, o ciclo de moda pode tornar-se mais lento. A ausência de proteção para designs e a existência de um regime de livre apropriação acelera a difusão de tendências e induz mais rapidamente a obsolescência de designs. 0 ciclo de moda é conduzido mais velozmente devido à difusão da cópia de designs, uma vez que as cópias desgastam a posição das mercadorias de moda. A pirataria beneficia paradoxalmente esse processo, induzindo uma renovação de estoque e consequentes vendas adicionais.

Com um regime de livre apropriação, a pirataria, segundo Raustiala e Springman (2006), contribui para a rápida produção de novos designs inspirados criativamente pelos originais. Além disso, parte das cópias não é reprodução literal de alguns originais, pois se constituem como objetos compostos de elementos relançados como um trabalho derivativo. As variações produzidas sob explorações irrestritas de derivativos contribuem para produzir diferenciação que induz o consumo, porque há aqueles que preferem uma variação particular do original. Sobre isso, Carvalho (2011) desenvolveu uma investigação em que observou o comportamento de muIheres de classe média alta da cidade de Cuiabá. As mulheres preferiam pagar por bolsas de marcas conceituadas no mercado, em que elas pudessem remanejar algumas características dos produtos, montando peças que não se encontram nos catálogos dessas marcas, constituindo-se como cópias com detalhes adicionais.

Raustiala e Springman (2006) referem que a baixa proteção ao regime de propriedade intelectual na indústria da moda é um exemplo de gerenciamento descentralizado de inovação, porque mais empresas se empenham no desenvolvimento de designs via produção de cópias e derivativos, como aquelas que compõem a indústria varejista. Os varejistas preferem a baixa proteção, pois esse regime lhes permite copiar designs para vendê-los a preços variados. Em contraste, o sistema centralizado de inovação é controlado por uma empresa ou um número reduzido de empresas que reclamam direitos de propriedade intelectual, ao preferirem um regime de alta proteção. Em regiões onde há mais baixa proteção à propriedade intelectual, mais mercadorias são consumidas porque as cópias reduzem o 
status expressado pela novidade de designs, conduzindo ao fato de que parte dos consumidores procurará por novas tendências. A indústria da moda dos Estados Unidos, a que Raustiala e Springman (2006) se referem, floresce, ainda que haja uma proteção menos acirrada ao design dos produtos de moda lá fabricados.

Sinnreich e Gluck (2005) aprofundam uma perspectiva sobre a Moda que intercepta a proteção à propriedade intelectual. A Moda possui uma das indústrias mais cíclicas que abrange a produção de designs, e o que a torna diferente de outras indústrias é o fato de considerar, em parte, a admissão de fontes de inspiração, gerando conflitos relativos aos interesses de quem, por direito, reclama a origem dessas fontes. Antes de ponderar sobre a proteção intelectual que caracteriza as normas que regem a legislação, a indústria da moda é regulada por códigos e convenções sociais, porque a Moda manifesta as relações entre indivíduos e culturas (BRANDINI, 2007), inclusive, por meio das roupas. Dado o destaque da roupa, é relevante mencionar que ela é um dos aspectos que pode evidenciar a importância das relações sociais (BARNARD, 2003). Sinnreich e Gluck (2005) continuam seu pensamento ao explicarem que, no que tange à abrangência da indústria que setoriza a fabricação de roupas, a Moda constitui-se como um dos mais visiveis marcadores sociais contemporâneos que expressam afiliação, escolha do estilo de vida e identidade. Ao passo que a Moda tem sido utilizada para expressar alianças sociais e conformidade ideológica, também representa uma manifestação centrada nas agitações e nos inconformismos das sociedades. Essa contradição evoca a nível individual uma inocuidade a respeito das decisões sobre atividades cotidianas (como a decisão do que se deseja vestir). Porém, diante de um panorama coletivo, a Moda é alvo do controle social de governos, de religiões e de uma sorte de instituições que nela tem observado um valor que se dirige à manipulação de códigos, ao prescrever e banir o vestuário que não se adequa à perspectiva cultural estabelecida. Além do mais, na sociedade contemporânea, a Moda surge como uma entidade comercial conduzida por forças que se centram na demanda de produção alavancada pela obsolescência planejada. A propriedade intelectual emerge nessa paisagem facetada que abrange economia, política e sociedade por intermédio de aspectos complexos, que se tornam dificeis de policiar e de serem cumpridos, em razão também das mudanças das últimas tendências tecnológicas e culturais que, a exemplo da estrutura da Moda, apresentam efemeridade constante. Além dessas perspectivas levantadas, Sinnreich e Gluck (2005) aconselham: no intuito de tornar a inovação efetiva, designers de moda devem operar dentro de um ambiente que admita acesso a ideias e permita aos designers utilizá-las a partir de caminhos novos e abertos que propiciem uma constante criatividade. 


\section{Considerações finais}

A fabricação e a comercialização de cópias não autorizadas surgem como um componente disruptivo para um modelo de desejo orientado para classes que consomem a exclusividade. Isso anuncia uma rota de quebra do modelo econômico formal. A indústria da moda - nomeadamente ( $\mathrm{e}$, em especial) as corporações multinacionais - é parte de um dos setores que apoia a censura à prática das cópias não autorizadas, ao inclinar-se pelo esforço de reprová-la por não se adequar aos modelos culturais, econômicos, jurídicos, políticos e sociais que se impõem para fortalecer a própria indústria.

No que tange à emergência de leis que protegem a propriedade intelectual, ergue-se uma lógica que prioriza alguns produtos em detrimento de outros. Dentro dessa lógica, uma divisão que categoriza proteções reconhece diferenças entre os tipos de bens que a lei assegura, demarcando origem e elevando qualidade a uns e rebaixando outros à marginalização, a fim de perpetuar uma coerência em que o modelo marginal se dirija a qualquer tipo de cópias não autorizadas, ainda que elas possam trazer algum tipo de benefício financeiro a um mercado em ascensão.

Os caminhos que as cópias percorrem rompem paradigmas de funcionamento da formalidade, ao questionarem lugares rigidamente estabelecidos pela legislação e pelo poder público. Ainda que haja uma censura referente à prática das cópias na indústria da moda, erige-se uma resistência dessa prática devido ao seu forte poder de transgressão, ao acesso relativo ao sistema produtivo e ao alcance facilitado do consumo.

Recebido: $15-10-2018$

Aprovado: 5-12-2018 


\section{REFERÊNCIAS}

AFP. Justiça reconhece exclusividade das solas vermelhas de Louboutin: Christian Louboutin criou sua marca nos anos 1990, que foi popularizada por estrelas de cinema e televisão, 13 jun. 2018. Estadão. Disponivel em: https://cultura.estadao.com.br/noticias/geral,justica-reconheceexclusividade-das-solas-vermelhas-de-louboutin,70002348640. Acesso em: 21 jan. 2019.

ANSA. Contrafação: loja em Veneza vendia lenços falsos Versace. Fashion Mag, 29 out. 2014. Disponivel em: http://pt.fashionmag.com/news/Contrafacao-Loja-em-Veneza-vendia-lencos-falsosVersace,439468.html\#.VaUJj3iMifS. Acesso em: 14 jul. 2015.

ARAÚJO, Allex Rodrigo Medrado. Dogma95, dispositivos móveis e experiências tremidas: em favor da legitimação do discurso amador. In: ENCONTRO DA ASSOCIAÇÃO NACIONAL DOS PESOUISADORES EM ARTES PLÁSTICAS (ANPAP), 20, 2011, Rio de Janeiro. Anais [...] Rio de Janeiro, 2011. p. 3187-3201. Disponivel em: http://www.anpap.org.br/anais/2011/pdf/cpa/allex_rodrigo_ medrado_araujo.pdf. Acesso em: 12 jul. 2016.

AZEVEDO, Wilton. 0 que é design? 4. ed. São Paulo: Editora Brasiliense, 2014. Coleção Primeiros Passos, v. 211.

BALDINI, Massimo. A invenção da moda: as teorias, os estilistas, a história. Tradução de Sandra Escobar. Lisboa: Edições 70, 2006. Título original: "L'Invenzione della Moda. Le teorie, gli stilist, la storia".

BARBOSA, Denis Borges. Uma introdução à propriedade intelectual. 2. ed. Rio de Janeiro: Editora Lumen Juris, 2003.

BARNARD, Malcom. Moda e comunicação. Tradução de Lúcia Olinto. Rio de Janeiro: Rocco, 2003. Titulo original: "Fashion as communication".

BECKER, Howard S. Outsiders: studies in the sociology of deviance. Nova lorque: The Free Press, 1973.

BOSTEELS, Karin. No patent for Louis Vuitton's checkboard pattern. Retail Detail, 4 maio 2015. Disponivel em: http://www.retaildetail.eu/en/news/no-patent-louis-vuittons- checkerboard-pattern. Acesso em: 1 ago. 2016.

BRANDÃO, Ludmila. Ensaio sobre a cópia na era da hiper-reprodutibilidade técnica. In: PRECIOSA, Rosane; MESOUITA, Cristiane (orgs.). Moda em ziguezague: interfaces e expansões. São Paulo: Estação das Letras e Cores, 2011. Cap. 19, p. 195-212.

BRANDÃO, Ludmila. 0 "camelódromo", a cidade e os fluxos globais subalternos. Pós: Revista do Programa de Pós-Graduação em Arquitetura e Urbanismo da FAUUSP, São Paulo, n. 25, p. 232-251, jun. 2009. Disponivel em: $h$ ttp://www.revistasusp.sibi.usp.br/pdf/posfau/n25/15.pdf. Acesso em: 10 out. 2011.

BRANDINI, Valeria. Vestindo a rua: comunicação, moda \& metrópole. Revista Fronteiras: estudos midiáticos, v. 9, n. 1, p. 23-33, jan./abr. 2007.

BRASIL Lei n. 9 9.279, 14 de maio de 1996. Regula direitos e obrigações relativos à propriedade industrial. Diário Oficial da União, Brasilia, DF, 14 maio 1996. Disponivel em: http://www.planalto. gov.br/ccivil_03/Leis/L9279.htm. Acesso em: 18 jan. 2017.

CARVALHO, Carla Gavilan. Pirata, mas classe A: sobre o consumo subalterno da pirataria de luxo. Dissertação (Mestrado em Estudos de Cultura Contemporânea) -Instituto de Linguagens, Universidade Federal de Mato Grosso, Cuiabá, 2011.

COSTA, Carlos Alberto Franco da. Desigualdade e a crise financeira mundial: o dinheiro financeiro e a maior concentração de renda da história. In: SEMINÁRIO INTERNACIONAL HISTÓRIA DO TEMPO PRESENTE, 2, 2014, Florianópolis. Anais do II Seminário Internacional do Tempo Presente. Florianópolis, 2014. p. 1-10. Disponivel em: http://eventos.udesc.br/ocs/index.php/STPII/ tempopresente/paper/viewFile/111/54. Acesso em: 14 jul. 2015.

DORION, Eric Charles Henri et al. Brazilian Entrepreneurship Reality: A Trilogy of Imitation, Invention and Innovation. In: BURGEUER-HELMCHEN, Thierry (ed.). Entrepreneurship - Creativity and Innovative Business Models. Croatia: InTech, 2012. p. 82-98.

GORZ, André. O imaterial: conhecimento, valor e capital. Tradução de Celso Azzan Júnior. São Paulo: Annablume, 2005. Título original: "L'immatériel: connaissance, valeur et capital". 
JACOB, Kamila Grabriela et al. Abordagens da estratégia inovativa de imitação (cópia) na indústria de vestuário. Sistemas \&t Gestão, v. 9, n. 1, p. 156-166, 2014.

KILCOOLEY-O'HALLORAN, Scarlett. Louis Vuitton loses checkboard case. Vogue News, 1 maio 2015. Disponivel em: http://www.vogue.co.uk/news/2015/05/01/louis-vuitton-loses-damier-trademarkinfringement-case-checkerboard-motif. Acesso em: 1 ago. 2016.

KINSELLA, Stephan. Against Intellectual Property. Auburn: Ludwig von Mises Institute, 2008.

KNOLL, Susy Bello; ECHEVERRIA, Pamela. La moda, el derecho e la RSE: relaciones e intercambios entre 3 universos. Tiempo Argentino, ano 51, 6 jul. 2014. Disponivel em: http://fonres.com/panel/ upload/file/23-SuplementoRS_TiempoArgentino_06.07.2014_Final.pdf. Acesso em: 15 out. 2015.

KRETSCHMANN, Ângela. 0 feudalismo no direito autoral: um mal necessário? In: SIMÃO, José Fernando; BELTRÃO, Silvio Romero (coords.). Direito civil: estudos em homenagem a José de Oliveira Ascensão: teoria geral do direito, bioética, direito intelectual e sociedade da informação. v. 1. São Paulo, Atlas: 2015.

KUR, Annette; DREIER, Thomas. European Intellectual Property Law: text, cases and materials. Cheltenham: Edward Elgar Publishing Limited, 2013.

LIMA, Carmen Lucia Castro. Politicas culturais para o desenvolvimento: o debate sobre as indústrias culturais e criativas. In: ENCONTRO DE ESTUDOS MULTIDISCIPLINARES EM CULTURA, 3, 2007, Salvador. Anais do 3. ${ }^{\circ}$ Encontro de Estudos Multidisciplinares em Cultura. Salvador: Faculdade de Comunicação, Universidade Federal da Bahia, 2007. Disponivel em: http://www.cultufba.br/ enecult2007/CarmenLuciaCastroLima.pdf. Acesso em: 18 jan. 2017.

LIPOVETSKY, Gilles. Luxo eterno, luxo emocional. In: LIPOVETSKY, Gilles; ROUX, Elyette. 0 luxo eterno: da idade do sagrado ao tempo das marcas. Tradução de Maria Lúcia Machado. São Paulo: Companhia das Letras, 2005. Título original: "Le luxe éternel: de l'âge du sacré au temps des marques".

LO, Mouhamadou Moustapha. Os direitos de propriedade intelectual. In: AMBROSI, Alain; PEUGEOT, Valérie; PIMIENTA, Daniel. (coords.) Desafios de Palavras: enfoques multiculturais sobre as sociedades da informação. Caen: C¿tF Éditions, 2005.

LOPES, Humberto Pinheiro; VERAS, Emanuelle Kelly Ribeiro da Silva. Chafurdos em ziguezague: metodologias de uma pesquisa de moda mediada pela cultura visual. In: COLÓOUIO DE MODA, 8, 2012. Anais [...] Disponivel em: http://www.coloquiomoda.com.br/anais/Coloquio\%20de\%20 Moda\%20-0202012/GT08/COMUNICACAO-ORAL/103300_Chafurdos_em_ziguezagues.pdf. Acesso em: 15 jul. 2018.

LOPES, Humberto Pinheiro. Chafurdos na Moda: heróis e vilões na história das cópias. Goiânia: Editora da UFG, 2014. Coleção Expressão Acadêmica.

LOPES, Humberto Pinheiro. Prática das cópias: censura e reconhecimento na indústria da moda. Tese (Doutorado em Estudos Contemporâneos) - Instituto de Investigação Interdisciplinar, Centro de Estudos Interdisciplinares do Século XX, Universidade de Coimbra, Coimbra, 2017.

MARINHO, Maria Edevalcy; OLIVEIRA, Liziane Paixão Silva. 0 uso de precedentes judiciais de jurisdições estrangeiras em matéria de propriedade intelectual. In: MARINHO, Maria Edevalcy; SILVA, Solange Teles da; OLIVEIRA, Liziane Paixão Silva (orgs.). Diálogo entre juizzes. Brasilia: UniCEUB, 2014. p. 209-222.

MARTINELI, Fernanda. Pirataria S.A.: circulação de bens, pessoas e informação nas práticas de consumo. Tese (Doutorado em Comunicação e Cultura), Universidade Federal do Rio de Janeiro (UFR), Rio de Janeiro, 2011.

MARTINELI, Fernanda. Pirataria.org: comunicação, consumo e organização social. In: COMUNICON, 2012. Anais do Comunicon. São Paulo: PPGOM, Escola Superior de Propaganda e Marketing, 2012.

MARTINS, Raimundo. Implicações da ideia de crise para a compreensão da experiência visual. In: ENCONTRO DA ASSOCIAÇÃO NACIONAL DE PESOUISADORES EM ARTES PLÁSTICAS, 18, 2009, Salvador. Anais do 18.0 Encontro da Associação Nacional de Pesquisadores em Artes Plásticas. Salvador, 2009. p. 3715-3725. Disponivel em: http://www.anpap.org.br/anais/2009/pdf/ceav/ raimundo_martins.pdf. Acesso em: 15 jun. 2016.

MCDOUGALL, Andrew. Chanel wins court case to de-list counterfeit sites. Cosmetics design.com, $1 \mathrm{dez}$. 2011. Disponivel em: http://www.cosmeticsdesign.com/Regulation-Safety/Chanel-wins-UScourt-case-to-de-list-counterfeit-sites. Acesso em: 14 jul. 2015. 
MESQUITA, Cristiane Ferreira. Incômoda moda: uma escrita sobre roupas e corpos instáveis. Dissertação (Mestrado em Psicologia Clínica) - Pontificia Universidade Católica de São Paulo, São Paulo, 2000.

MESOUITA, Cristiane Ferreira. Moda contemporânea: quatro ou cinco conexões possiveis. 1. ed. São Paulo: Editora Anhembi Morumbi, 2010 (Coleção Moda e Comunicação).

MUELLER, Suzana Pinheiro Machado. A comunicação científica e o movimento de acesso livre ao conhecimento. Ci. Inf., Brasilia, v. 35, n. 2, p. 27-38, maio/ago. 2006. Disponivel em: http://www. scielo.br/pdf/\%0D/ci/v35n2/a04v35n2.pdf. Acesso em: 14 jul. 2015.

MUSTONEN, Natalia. Fashion openness: applying an open source philosophy to the fashion paradigma. Dissertação (Mestrado) - School of Arts, Design and Architecture, Aalto University, [s. I.], 2013.

PAZ, Augusto; SCHIMIDT, Fernanda. Falsificação afeta mais a imagem do que o bolso das grifes de luxo. UOL Mulher, 6 abr. 2015. Disponivel em: http://mulher.uol.com.br/moda/noticias/ redacao/2015/04/06/para-grifes-de-luxo-falsificacao-afeta-mais-a-imagem-do-que-o-bolso.htm. Acesso em: 14 jul. 2015.

RAUSTIALA, Kal; SPRINGMAN, Christopher. The piracy paradox: innovation and intellectual property in fashion design. Virginia Law Review, v. 92, n. 8, p. 1687-1777, dez. 2006.

SANT'ANNA, Mara Rubia. Teoria da moda: sociedade, imagem e consumo. Barueri: Estação das Letras e Cores Editora, 2007.

SANTOS, Maria Cecilia Loschiavo dos. Consumo, descarte, catação e reciclagem: notas sobre design e multiculturalismo. In: MORAES, Dijon de. Cadernos de Estudos Avançados em Design: multiculturalismo. 2. ed. Barbacena: Ed. UEMG, 2013.

SCHWEIDLER, Christine; COSTANZA-CHOCK, Sasha. Pirataria. In: AMBROSI, Alain; PEUGEOT, Valérie; PIMIENTA, Daniel. (coords.) Desafios de Palavras: enfoques multiculturais sobre as sociedades da informação. Caen: C\&tF Éditions, 2005.

SHERWOOD, Robert M. Propriedade intelectual e desenvolvimento econômico. Tradução de Heloisa de Arruda Villela. São Paulo: Editora da Universidade de São Paulo, 1992. Título original: "Intellectual Property and Economic Development".

SILVEIRA, Sérgio Amadeu da. Inclusão digital, software livre e globalização contra-hegemônica. Revista Parcerias Estratégicas, n. 20, p. 421-446, jun. 2005. Disponivel em: http://www.cgee.org.br/ arquivos/p_20_1.pdf. Acesso em: 14 jul. 2015.

SINNREICH, Aram; GLUCK, Marissa. Music \& Fashion: The Balancing Act Between Creativity and Control. The Norman Lear Center, p. 1-45, 29 jan. 2005. Disponivel em: https://learcenter.org/pdf/ RTSSinnreichGluck.pdf. Acesso em: 29 jun. 2016. 